MARKETING AND BRANDING
RESEARCH $\begin{gathered}\text { INDUSTRIAL } \\ \text { MANAGEMENT } \\ \text { INSTITUTE }\end{gathered}$

\title{
Designing the distribution network in a cassava supply chain in Thailand
}

\author{
Witchayut Timaboot ${ }^{*}$, Nanthi Suthikarnnarunai \\ University of the Thai Chamber of Commerce, Bangkok, Thailand
}

\begin{abstract}
Keywords:

Distribution Network, Cassava Supply

Chain, Rail

Transportation, Linear

Programming Model

Correspondence: witchayut_ti@hotmail. com

According to Thailand's infrastructure development and investment plan, an efficient transportation network will take form over the next three to five years. Dual-track railway will be built to cover more areas of the country and will be offered more routes between central, north-eastern, and eastern Thailand. Therefore, rail transportation or train transportation will become a good choice or an important conveyance of goods from various origins to various destinations in Thailand due to its competitiveness which is low cost of freight. This paper presents a concept of designing the new distribution network in Thailand using rail as a major mode of transportation. Cassava distribution chain is selected as a case study and prototype of this new design, since Thailand is an agricultural country and cassava is one the most exported agricultural product. Various factors influencing the choice of distribution network and transportation mode, such as customer satisfaction, characteristics of products, cost, etc., are investigated and are described. Linear programming models represent the current distribution model and the new distribution model are presented and then solved by Microsoft Excel with Open Solver Software. The result reveals that the new distribution network of cassava product in Thailand can lower the total distribution cost up to $51.63 \%$ compare to the current distribution network.
\end{abstract}

\section{Introduction}

Currently Thailand confronts a problem about transportation problem there are some limitations of transportation including maximum acceptable weight, traffic congestion and high fuel prices. For this reasons, a study of the new transport routes by trains was implemented so that we could get benefit from multimodal transportation according to Thai government's dual track railway development scheme for the effective transportation system. Therefore, the researchers built the decision-making model to determine the cassava 
purchasing centers along the same route where the dual track railway construction project will be implemented. Logistics development has largely been one of providing infrastructure as reflected in national modal transport development plans for road, rail, air and water transport. The situation is quite understandable because logistics is not a separate mode of transport, but rather a system for facilitating the effective and efficient trading and movement of goods. Logistics is a beneficiary of improved transport infrastructure and transport services. Banomyong, Thai, and Yuen (2015) pointed out that the project consists of the urgent work in dual track railway construction project involving many routes including Lop Buri - Pak Nampho, Mapkabao - ThanonChira Junction, ThanonChira - KhonKaen, NakhonPathom Hua Hin and PrachuapKhiri Khan - Chomphon, and the next dual track railway construction project includes Hua Hin - PrachuapKhiri Khan, Chumphon - SuratThani, Surat Thai-Padang Beza, Pak Nampho - Denchai, KhonKaen-NongKhai and ThanonChira - UbonRatchathani. In this research concentrate Lop Buri - Pak Nampho, Mapkabao - ThanonChira Junction, ThanonChira - KhonKaen, NakhonPathom - Hua Hin and PrachuapKhiri Khan - Chomphon were selected as the purchasing centers.

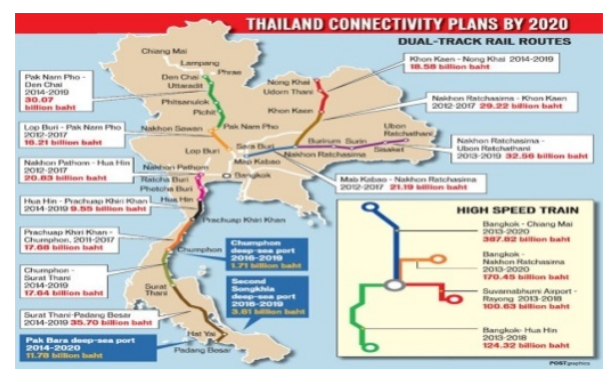

Figure 1. Map of dual track rail way from Thailand government policy in 2020

Therefore rail transportation or train transportation will become a good choice or an importance convenes of goods from variants origin variants destination in Thailand.

\section{Cassava Product in Thailand}

In today's business world, time is a very important factor for managing the bulk of the products in supply chains especially when the process is involved in a number of timeperiods. In this paper, a multiple period multiple product supply chain integrated with a location-allocation problem is formulated by Mousavi, Alikar, Akhavan Niaki, and Bahreininejad (2015). Thailand is the largest producer and exporter of cassava in Asia also in third of high production, whereby China is a major buyer of Thai cassava for the purposes of ethanol production and a wide range of food products. As Thailand has a large land area for crop production, cassava is widely planted in the regions of Thailand. 


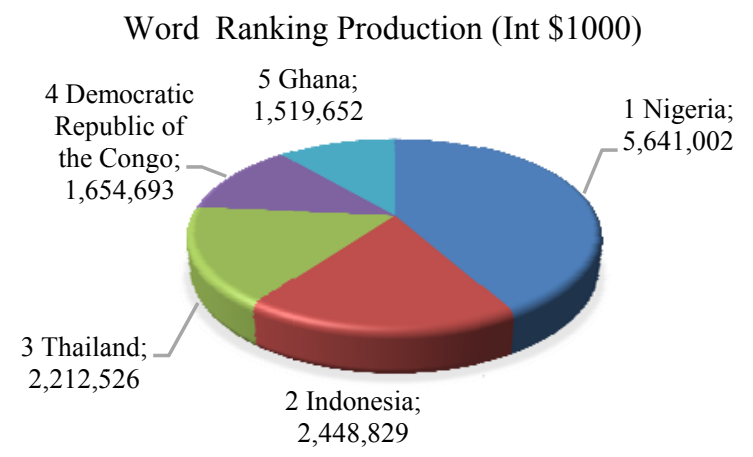

Figure 2.World Cassava productions ranking in 2015

At present, after cassava is harvested, famers will collect and load cassava into trucks to deliver it to a stock yard or a purchasing center. Then, land and waterway are modes of transportation in which it is found that transportation by truck incurs the highest cost. However, there is a variety of cassava transportation modes as well as transportation routes. Therefore, this research was conducted to study transportation routes to fit demand of the purchasing centers, and the chosen route was the transportation via dual track railway supported by Thai government to benefit the transportation sectors in the future as well as reduction of transportation cost. In addition, purchasing centers where the trains passed by were selected as a point of origin in order to convey goods to the seaport before those were shipped into vessels on Si Chang Island. There are small portions of delivering cassava by rail transport only some companies operate this transport. Nevertheless, there are several insufficient points in the multimodal transport; less than demand, too old or broken, low effectiveness fluctuation or uncertainty of transport, too short distance of double-track railways, etc. As competition in the market place intensifies and new technologies evolve, the firms are taking fresh looks at their distribution channels to squeeze out inefficiencies. As a result, many types of distribution channels have come into being ranging from the traditional retail channel to the direct sales model and the hybrid or multi-channel distribution system refer (Geng \& Mallik, 2007). In addition, some companies are located far from train stations so this kind to transportation is not worth it for them. As this service is rarely used, some companies which want to operate the multimodal transport must have large amount of product enough with the minimum designated quantity limited. Nowadays, logistics service companies (third party logistics providers) are responsible for the multimodal transport - road and rail transport- for cassava processing factories. The logistics company would rent some area at the destination station from the State Railway of Thailand, and bring some necessary equipment for moving goods containers to install at the train station, moreover, coordinate with the hirer and the Railway of Thailand staff to operate goods transportation from starting point until the destination. According to a study of quantity of cassava that agriculturists delivering in a short distance and an interview from traders, it was found out that in the supply chain, shipping companies likely calculate the delivery cost based on the shipping quantity- in other words, baht per kilogram the transportation from farm to processing company, and baht per ton for transportation from processing company others. In case of farer distance such as different provinces or cities, the delivery cost per unit will be more expensive and delivery costs will be calculated quite differently. In some cases, the hirer is disadvantaged or 
otherwise shipping company is. These consequences may occur unintended or intended because both parties usually negotiate the cost with each other using their experience and opinions. Basically, delivery cost should be calculated based on distance and quantity of product and the result will be bath per ton or kilogram, or by a popular method which is widely in overseas. In other words, delivering product regarding the delivery weight per a truck limited by law and the delivery cost will be calculated regarding the distance, and delivery service will be added if product loading-unloading is more than one time. There are several means of multimodal transport of cassava in Thailand but the main methods are delivering cassava product by road transportation with water transportation and delivering cassava starch by road transport with rail transport. Road transport with water transport by a barge is usually used for delivering cassava for a long time ago because it is comfortable, can save cost help unloading product from a barge to ship marine port at Koh Srichang quickly and effectively. According to a shipping company, there are some problems that usually found from delivery. Firstly, water level which decrease and increase depending on each season. As a result, water transport cannot be operated in some routes. Secondly, quantity and weight conditions, each time of delivery by a barge to Koh Srichang should have large quantity (at least 500 tons per delivery), in order to maintain balance of the ship when going to the sea. In terms of road transport, each operator hardly exchange product or ship on the going or returning way so ability of getting some other goods one the way back is still low. For the road transport with rail transport, it often used for delivering cassava starch only, as cassava ships and cassava pearl are often delivered to seaports at Koh Srichang, so they are transported by barge. Reason in the past, cassava transportation had poor management. It was usually transported from the farm each of destination. The products were transported from small groups directly to destination by truck. All goods were transport without calculating loss of the cost occurred using a large number of vehicles for transport without specifying limits of time. The transport was done in a long distance from farms to the purchase centers which located in different provinces. Farmers usually transported their products only by truck all along the way to the destination without swiping to some other ways which may be even more suitable. Therefore, the well-known transportation was limited at only road transportation. Road transport comes with various problems; traffic jams, uncertain time, security issues, limitation of the delivery amount, etc. These sometimes can be an important obstacle in transportation. To get more effective management of transportation, a new form of transportation has been designed to solve such issues. Thailand government will force dual track offer agriculture product. Therefore this paper presents concepts of desiring the new transportation network in Thailand using dual track railway mode as a major mode of transportation.

\section{Mode of Transportation}

While there are many articles that address the integration issues in production and distribution systems, many of these models only focus on transportation issues such as vehicle routing and Shipment size. Most of them do not consider how to allocation (Jang, Kim, \& Park, 2013). One of the important transportation components when considering about the necessity of transshipping goods is the transportation modes because each mode depends on the different requirement on carrying goods such as the air transportation is required in case of fast 
transport, shipping some goods in a big volume in a single round requires barge transportation, carrying goods to urban areas by car or truck is a convenient way to access any places and when carrying some goods in a large quantity to some accessible areas requires train transportation. However, the transportation mode selection depends on the customer requirement first. As Vender-managed inventory is a win-win situation: suppliers save on distribution and production costs since they can combine and coordinate demands and shipments for different customers, and buyers gain by not allocating re-source to controlling and managing inventories (Coelho, Cordeau, \& Laporte, 2012).

\section{Multimodal Transportation of Agricultural Goods}

In general, agricultural goods have low price and low value, so the most effective mode of transport is carrying these goods in a large volume. Normally, carrying the agricultural goods starts from the original farm to the final destination by collecting goods from each farm to the distribution point in order to carry goods in a large quantity to be worth to the transportation mode that may be by small truck, train or even a large ship. The manufacturer needs to make inventory allocation and shipment decisions. In particular, the number, size, and sequence of shipments should be determined. The inventory allocation policy is dependent upon these shipment decisions (Jang et al., 2013). Bassett (2015) pointed out that the optimization effect locations for supplier's selection, intermediate production, final production, terminals warehouses, and customers. Input-output-based commodity shipment model is integrated with a multimodal model of transportation network flows to predict the monetary value (Ham, Tschangho, \& Boyce, 2015). Each channel behaves strategically by taking into account its competitor's reactions while making the ordering decisions.

\section{Supply Chain Cassava}

Generally, the supply chain of the cassava will be considered in every phase of the product. Especially, after the harvest, cassava will have higher value when processed into other products, for example, flour produced from cassava plant which has low content of noncarbohydrate ingredient, namely, starch and it is well-known in world trade as tapioca flour. It is used directly for making in bakery industries, gelatinized products or processing into glucose, dextrin's and other products. When it comes to transportation, variety of delivery options will be conducted depending on each kind of cassava product; e.g. bulk, big bag, as well as various method of transportation will be involved, such as, by truck, railway or ship. After cassava harvest, the product is usually made dry, so there is no bad effect to its quality even transportation takes much time. According to some recent researches, many choices of storage are created to be selected, as well as many levels of transportation by designing a mathematic demonstration to help them make a decision of transportation to several ways. They use programs of AMPL with CPLEX or Lindo, Matlab or advance software for instance, to consider and make a decision in which the programs are controlled by a parameter, varied by desired coefficients. Discrete event simulation has long been a useful tool for evaluating the performance of such systems. However, simulation can only evaluate performance of given system alternatives, which is often insufficient from the optimization point of view (Lee, Chew, Teng, \& Chen, 2008). On the other hand, this research uses a program which already installed in the Microsoft Office Excel. To make a decision of which transportation 
should be organized, you can use a function installed in "add on" instruction of data called "Solving" which is easy to understand and suitable for processing small database, and therefore it can help making decision faster. The simulation-based optimization method to deal with such system complexity; while simulation models capture arbitrary levels of operational detail, optimization via simulation provides an efficient way to minimize average total cost.

\section{Factor Analysis}

Since the market terms assess the location, customer, difference area to locate the distributer also determine factor to reduce the transportation cost regarding to the volume of product (Mousavi et al., 2015).To make a decision, technically, all relating factors are considered in order to get the lowest cost and the highest profitability. Most of operators tend to consider customers' demands as the first priority without considering other effects which may lead to decrease of profit. In order words, conducting transportation according to the customers' demands may cause some loss; the operators choose a transportation mode which takes the shortest lead time but of course, it comes with high cost, or they use transportation with the lowest cost but it impacts delivery due date, for instance. To get the most benefits in terms of transportation, two main things are often taken into account including customers' demands and cost that agreed by the customers. The model formulation is motivated by the following scenario with factor impacted. This contribution to interregional trade modeling has principal objective (Ham et al., 2005). Customers' needs may impact to company's profitability or income which determines conditions of product distribution which is suitable to the network. The majority of customers focus on delivery due date, flexibility, being able to return the product in case of dissatisfaction. However, agricultural products cost low price, so it hardly be returned or refunded but the operators would rather pay penalty to customers and destroy the product. Therefore, it is no doubt that if the operators can improve to meet with the customers' needs, their product delivery will be more effective relatively. This research is to analyze influent and crucial factors that are necessary for transportation needs.

\section{Quantities of Cassava to Be Transported to the Purchasing Centers}

According to the study and selection of the starting points for cassava exportation, the research revealed that Thailand was capable of producing a large number of cassava in which the areas of growing were in all regions including the northeast, the north, the east and the west of Thailand. Meanwhile, there was so rare for cassava-growing areas in the central and the south of Thailand due to unfavorable weather conditions. Creation of the model by collecting data from all cassava-growing areas would be excessive resulting in unsuccessful all data processing. Therefore, the researchers selected twenty-growing areas, and the details of which were provided sample twenty areas as below. 
Table 1

Indicated the Quantities of Cassava from the Different Areas

\begin{tabular}{lcl}
\hline Farms & Capacity (Tons) & Regions \\
\hline Kornburi & 765,11 & Nakornratchasrima \\
Seungsan & 750,34 & Nakornratchasrima \\
Nongboonmag & 742,59 & Nakornratchasrima \\
Kanuworaburi & 694,67 & Kampangpet \\
MuangKampangpet & 632,73 & Kampangpet \\
Dan KhunThot & 612,76 & Nakornratchasrima \\
Soidao & 500,76 & Chantaburi \\
KhlongLan & 429,71 & Kampangpet \\
Sikhio & 403,54 & Nakornratchasrima \\
Sanam Chai Khet & 398,63 & Chachoengsao \\
Mae Wong & 372,20 & Nakornsawan \\
ThepSathit & 353,54 & Chaiyaphum \\
Lao Khwan & 347,95 & Kanchanaburi \\
Nam Yuen & 342,63 & Ubonratchatani \\
ladyao & 336,29 & Nakornsawan \\
SaiYok & 323,98 & Kanchanaburi \\
ThaTakiap & 305,99 & Chachoengsao \\
Wang Sombun & 274,10 & Sa Kaeo \\
Sung Noen & 262,09 & Nakornratchasrima \\
Khlong Hat & 258,72 & Sa Kaeo \\
\hline
\end{tabular}

Source: Centre for Agricultural Information, Office of Agricultural Economics, 2015

Concerning Table 1 indicated that the quantities of cassava in those twenty-growing areas came from data collection for a period of one year that collect from all area in Thailand base on high volume output.

\section{Current Transportation Routes for Adjustment to the New Routes}

Transportation used in cassava's supply chain is mainly by road transport. According to an investigation, famers usually use a small tractor to deliver product from farms to small purchasing centers. This kind of transport consumes high energy. In order words, they do not load the product in maximum amount which a tractor can go. Therefore, gathering products from farmers in the same tractor would help solve the problem. For delivery out from factory, a bigger truck (from 6-wheel to container pooling) is used. With this way of transportation, it will support energy saving which affect to cost saving as well. According to a research of cassava logistics currently, fresh cassava from farmers will be transferred to ports through processing to cassava chips, cassava pearl and cassava starch. By this, the average logistics cost from the farmers to seaport of cassava chips and cassava pearl is THB1,917.87 per ton in which transportation cost is approximately 45 per cent of the total logistics cost, followed by loss (about 30 per cent of the total logistics cost). The logistics cost for cassava starch is about THB 2,528.03 in which transportation cost is 47 per cent and loss is 10 per cent. As Thailand has limitations of basic structures, double-track railway system, fuel price which constantly increasing, and high risk of loss during processing, for instance, so all relating sections should enhance and promote business operators to use alternative energy for transport and processing 
in order to reduce cost in a long run, moreover, promote farmers to produce clean cassava chips to add value into the products before selling to the processing factory, as well as promote manufacturing companies to product good quality of cassava product. A new network will design by consolidate from each original point (cassava farm) ship to destination where a dual-track train station then these cassava will transit to Ayuthaya Station where a closest a river port for preparing transport to Koh Srichang (Ship marine port).

\section{Decision-making Model was Built under Conditions of Quantities, Cost, and Routes}

For the design of such model, it is the planning of all these functions and sub-functions into a system of goods movement in order to minimize cost and maximize service to the customers (Tseng, Yue, \& Taylor, 2005), the following was built based on relationship between factors and conditions to formulate Linear Programming with the following details: The total minimum cost Min Z;

$$
\sum_{i=1 j=1}^{I} \sum_{w=1}^{J} \sum_{\mathrm{ijw}}^{W} \mathrm{Q}_{\mathrm{ijw}}
$$

$i$ means a point of origin of cassava transportation in different areas $\mathrm{j}$ means a cassava purchasing center at each train station, $\mathrm{C}$ means cost - baht/ton calculated by distance $\mathrm{x}$ cost (baht/ton/k.m.) Q means transport volume (unit: ton). All cost occurrence combined every path form the transit routes and all mode, $i$ is determine an original farm that using 20 areas as table $I, j$ is determine a station of railway where use for purchasing point total 12 stations as detail above

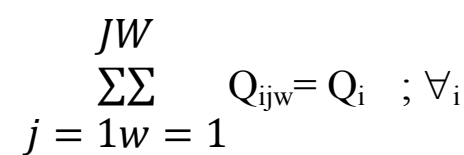

Total quantities of cassava in different areas (i) transported to the purchasing centers (j) by truck transportation modes by 4-wheel truck, 6-wheel truck and semi-trailer (10 wheels). In the distribution part, we consider many different transportation types as Sun, Chung, and Chan (2015) whereby the overall weights shall not be excessive from the point of origin. $W$ means cassava transportation modes from the points of origin in different areas, maximum weight limit and cost per unit. $\mathrm{Q}_{i}$ means total quantities of cassava from each point of origin in previous research. The considering capacity restriction on distribution center is a limit on number of vehicles delivered thought single distribution center (Eskigun, Beaujon, Tew, Preckel, Uzsoy, \& Krishnan, 2005). The basic inventory allocation problem has been studied in various contexts.

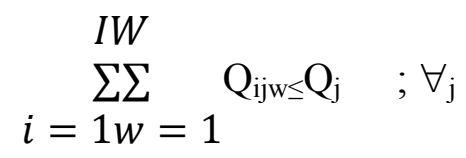

Total quantities of cassava in different areas (i) transported to the purchasing centers (j) by any types of vehicles must not exceed purchase ability $\left(\mathrm{Q}_{\mathrm{j}}\right)$. 


$$
\sum_{i=1 j=1}^{I J} \mathrm{Q}_{\mathrm{ijw}} \quad \leq \mathrm{Q}_{\mathrm{w}} \quad ; \forall_{\mathrm{w}}
$$

Monteiro, Rossetti, Campos, and Kokkinogenis (2014) pointed out that this model has two sub models that intervene of weight which truck load available. Total quantities of round trips (i) transported to the purchasing centers (j) by all types of vehicles must not exceed the maximum weight limit that round trip number consider by transportation each route divide a truck load limit that show in table IV that summary of round trip is not more than number of available at each original determine $\left(\mathrm{Q}_{\mathrm{w}}\right)$. The allocation of production volumes among multiple manufacturing sites involves many quantitative and qualitative variables and constraints (Kheong \& Jiao , 2004). However, many studies (Jang et al., 2013) use simple assumptions in their models.

Table2

Indicated Cost per Unit for Transportation by each Type of Vehicle

\begin{tabular}{cc}
\hline Truck Mode & Transportation Cost (Kilometers/Tons) \\
\hline 4 Wheels & 6.44 \\
6 Wheels & 5.08 \\
10Wheels & 6.63 \\
\hline
\end{tabular}

Referred to fuel price 29.94-33.44 Baht/Litre

Table3

Indicated Limitation of Transportation in each Type of Vehicle

\begin{tabular}{cc}
\hline Truck Mode & Transport Round Limit \\
\hline 4 Wheels & 500.00 \\
6 Wheels & 100.00 \\
10Wheels & 20.00 \\
\hline
\end{tabular}

Concerning Table 3, it showed assumption limitation of round transportation according to validation of a simulation model when demand carry each mode all destination.

Table4

Indicated Maximum Weight Limit in each Type of Vehicle

\begin{tabular}{cc}
\hline Truck Mode & Truck Carry Limit (Tons) \\
\hline 4 Wheels & 2 \\
6 Wheels & 12 \\
10 Wheels & 30 \\
\hline
\end{tabular}

\section{Results}

This paper from the view of transportation cost on the optimal, comprehensively considered the transportation time and the modes of transportation capacity constraints, solve the problem of this simulation be used as a model of transportation selection regarding a concept of setting related factors in the transport of cassava products in Thailand domestic by using the main multimodal transport patterns are; first delivery of cassava product by road and water transport and second delivery of cassava starch by road and rail transport. 
Transportation by road together with water with barge are used to deliver cassava products because they help save delivery cost the most effectively and comfortable for unloading product to ship marine port at Koh Srichang. This pattern of multimodal transport will maximize effectiveness of transportation because it can increase quantity of goods and help save energy as well as save delivery cost. On the other hand, road transport with rail transport, currently are used only for delivering exported cassava starch which is still in a small portion because this kind of multimodal transport is still lack of readiness. The Thai government is trying to improve basic structure of rail transport by investing more than 10,000 million baht to expand double-track railways to develop railways system and link transportation from the north and north-east to LeamChabang port. To solve problem of operation from the multimodal transport by road and rail, this study suggests a technique of situation simulation using computer programs. According to the calculation result shown in the decision-making model, it suggested which routes incurred the minimum transportation cost as well as maximum allowable weight. The following results were the transportation routes evaluated by the decision-making model: Khon Buri-Chira Junction, Soeng Sang- Chira Junction, Nongbunmak- Chira Junction, Khanu Woralaksaburi-Pak Nampho and Mueang Kamphaeng Phet-Pak Nampho in which all necessary expenses were in accord with the defined cost involving capabilities of goods delivery-purchase, maximum allowable weight, number of trucks used for shipping in single time as well as the minimum transportation cost. The findings of the research suggested that transportation by 6-wheel trucks incurred the minimum cost with quite high load capacity, and all costs incurred by the transportation was $14,930,676,031.05$ baht in which it could reduce the transportation cost to $51.63 \%$ other than non-predetermined cost. Furthermore, a new decision-making model was built with vehicle restrictions to assist in decision-making relating to transportation to the purchasing centers along the same route where the dual track railway construction project will be implemented so that we could benefit from multimodal transportation. Moreover, a reliable transportation network is a network that can recover from any disruption by preventing, absorbing, or mitigating its effects. Unexpected incidents like traffic jam, accidents, storms, hurricane, etc (Steadie Seifi, Dellaert, Nuijten, Woensel, \& Raoufi, 2014). There were not many functions of the decision-making model for a variety of transportation options. Therefore, the results processed by the model may not be accurate as it could evaluate up to 200 series only. The model present with single period problem if necessary the model can be straightforwardly extended to the multiple situations that able make more satisfied (Jang et al., 2013). Moreover, number of trucks used for shipping in a single time was test by assumption for validation of a simulation model. If there were formal research procedures, the data taken could be more accurate. Another, it is considered as the only transportation costs vary with distance from each location and fuel cost, Also this transportation route still use truck to railway mode then carry to river port where a last consolidate point before carry all by barge to ship marine port not mention about double handling cost that might be affect to total cost when goods have transited. So to get the maximum benefit the design of the network route should be used for transportation costs as lowest as possible. Double handling cost to a minimum. This may include other operation activity that make cost occurred. Development of road and rail transport together with other transport method would help increase a range of 
transport selection for other products in order to promote transport efficiency more lower cost. If the government is not ready for investment, it may consider letting private companies or foreign companies be investment partners under concession system in order to speed up the project to be able to respond to the demand of transportation, and cover all areas around the country. Furthermore, the government should consider turning the State Railway of Thailand to a public enterprise in order to improve services and increase effectiveness of work to be the same level of private enterprise. Rail transportation development will help reduce logistics cost in Thailand largely and rapidly develop the logistics in Thailand very well.

\section{References}

Banomyong, R., Thai, V. V., \& Yuen, K. F. (2015). Assessing the national logistics system of Vietnam. The Asian Journal of Shipping \& Logistics, 31(1), 21-58.

Bassett, M., \& Gardner, L. (2010). Optimizing the design of global supply chains at Dow Agro Science. Computers \& Chemical Engineering, 34(2), 254-265.

Coelho, L. C., Cordeau, J. F., \& Laporte, G. (2012). The inventory-routing problem with transhipment. Computers \& Operations Research, 39(11), 2537-2548.

Eskigun, E., Beaujon, G., Tew, J. D., Preckel, P. V., Uzsoy, R., \& Krishnan, S. (2005). Outbound supply chain network design with mode selection, lead times and capacitated vehicle distribution centres. European Journal of Operational Research, 165(1), 182-206.

Geng, Q., \& Mallik, S. (2007). Inventory competition and allocation in a multi-channel distribution system. European Journal of Operational Research, 182(2), 704-729.

Ham, H., Tschangho, J. K., \& Boyce, D. (2012). Implementation and estimation of a combined model of interregional multimodal commodity shipments and transportation network flows original research article. Transportation Research Part B, 39, 65-79.

Jang, W., Kim, D., \& Park, K. (2013). Inventory allocation and shipping when demand temporarily exceeds production capacity. European Journal of Operational Research, 227(3), 464-470.

Kheong, N., \& Jiao, J. (2004). A domain-based reference model for the conceptualization of factory loading allocation problems in multi-site manufacturing supply chains. Technovation 24(8), 631-642.

Lee, L. H., Chew, E. P., Teng, S., \& Chen, Y. (2008). Multi-objective simulation-based evolutionary algorithm for an aircraft spare parts allocation problem. European Journal of Operational Research, 189(2), 476-491.

Monteiro, N., Rossetti, R., Campos, P., \& Kokkinogenis, Z. (2014). A framework for a Multi-modal transportation network: An agent based model approach. Transportation Research Procedia, 4, 213-227.

Mousavi, M., Alikar, N., Akhavan Niaki, T., \& Bahreininejad, A. (2015). Optimizing a location allocation-inventory problem in a two-echelon supply chain network: A modified fruit fly optimization algorithm. Computers \& Industrial Engineering, 87, 543-560.

Steadie Seifi, M., Dellaert, N. P., Nuijten, W., Woensel, T. V., \& Raoufi, R. (2014). Multimodal freight transportation planning: A literature review. European Journal of Operational Research, 233(1), 1-15.

Sun, X. T., Chung, S. H., \& Chan. T. S. (2015). Integrated scheduling of a multi-product multi-factory manufacturing system with maritime transport limits. Transportation Research Part E: Logistics \& Transportation Review, 79, 110-127.

Tseng, Y. Y., Yue, W. L., \& Taylor, M. (2005). The role of transportation in logistic chain. Proceedings of the Eastern Asia Society for Transportation Studies, Korea, 5, 1657-1672. 